\title{
Una aproximación a las actitudes hacia la diversidad sexual en la infancia: el juego de la casa de colores
}

\section{Attitudes towards sexual diversity in children: the game of the house of colors}

\author{
Nuria Álvarez Rodríguez, María Victoria Carrera-Fernández, Xosé Manuel Cid-Fernández \\ Universidade de Vigo
}

\begin{abstract}
Resumen
En este trabajo se analizan las actitudes hacia la diversidad sexual en niñas/ os de $6^{\circ}$ de Educación Infantil. La investigación se llevó a cabo en un CEIP de Galicia con un total de 24 alumnas/os. Se llevó a cabo un estudio cualitativo, poniendo en práctica un juego que consistía en la lectura y visionado del cuento-"La casa de colores"- donde se presentan diferentes tipos de familias, incluyendo familias homparentales, y se realizabauna entrevista individual. En general, los/as niños/as niegan la existencia de la homoparentalidad Asimismo sus respuestas y elecciones se sitúan en la línea del rechazo social hacia las familias homosexuales. Palabras clave: Actitudes hacia la diversidad sexual; socialización de género; escuela; familia; igualdad; infancia.
\end{abstract}

\section{Abstract}

The aim of this study is to analyze attitudes towards sexual diversity in girls and boys of 6th grade in Early Childhood Education. The research was carried out in a CEIP of Galicia with a total of 24 students. A qualitative study was carried out, putting into practice a game that consisted of reading and viewing the story - "The house of colors" - where different families were presented including homoparental families- and an individual interview was conducted. In general, children deny the existence of homoparentality. Likewise, their answers and choices are in the line of social rejection towards homosexual families.

Keywords: Attitudes towards sexual diversity; Gender socialization; kindergarten; family; equality; childhood.

\section{Introducción}

El proceso de socialización permite la interiorización de conceptos, valores e ideas, sin que seamos casi conscientes de ello, especialmente en la infancia, donde la capacidad crítica no está tan desarrollada. Es por esto que, los estereotipos y los roles de género son tan importantes, así como la tarea de identificarlos. Según Lameiras, Carrera y Rodríguez (2013), los estereotipos son las creencias compartidas socialmente que se poseen acerca de un grupo social, incluyendo las características y los roles con los que se identifica a este grupo, creencias sin duda, simplistas y sesgadas. Concretamente los estereotipos de género son aquellas creencias compartidas por una sociedad sobre cómo deben ser y comportarse mujeres y hombres como sujetos pertenecientes a grupos distintos, desiguales y complementarios. Los estereotipos de género pueden clasificarse en dos grupos: estereotipos descriptivos y estereotipos prescriptivos. Los primeros hacen referencia a las características de las personas, tanto en el terreno intelectual y los rasgos de personalidad, como en el aspecto físico (mujeres frágiles y sumisas, que se tienen que mostrar bonitas; hombres valientes y con carácter, atléticos y fuertes); mientras que los prescriptivos serán los encargados de condicionar aquello que mujeres y hombres pueden realizar o no, será aquí donde entre la llamada esfera pública y privada (las mujeres se dedican preferentemente al hogar, independientemente de que tengan o no un trabajo remunerado, mientras que los hombres trabajan fuera de casa y no se corresponsabilizan en el ámbito doméstico).

La transmisión de los estereotipos a través de la socialización fomenta la continuidad del modelo heteropatriarcal, en el que la heterosexualidad estereotipo descriptivo- enseña las dos únicas formas socialmente legitimadas de ser persona: mujer, femenina $y$ heterosexual $y$ hombre, masculino $y$ heterosexual.

De esta forma, la socialización diferencial no implica exclusivamente una diferente categorización de identidades, que es impuesta, sino una imposición y jerarquización de identidades, constituyendo los hombres que reproducen la norma de género, el género hegemónico, mientras que las mujeres y todas aquellas personas que transgreden la norma de género, constituyen los grupos subordinados o identidades "ininteligibles" (Butler, 1993). Así, este proceso de socialización se construye sobre el sexismo y la homofobia o rechazo a la diversidad sexual (Carrera, Rodríguez, Lameiras, Vallejo y Alonso, 2013).

En esta línea, a través de la investigación realizada por Theimer, Killen y Stangor (2001) con 50 alumnos/as de preescolar (25 niñas y 25 niños) se evaluaron los comportamientos de exclusión en niños y 
niñas con dos tipos de juegos: juegos de muñecas y juegos de camiones, y con dos tipos de profesiones futuras: profesor/a y bombero/a a través de diferentes contextos de exclusión. Y se comprueba que niños y niñas prefieren jugar con parejas de su mismo sexo, de no ser así, las niñas están más a menudo excluidas de las actividades por los niños. Por otra parte, a la hora de elegir compañero o compañera están presentes los estereotipos que influyen en sus decisiones sociales, de modo que los niños y niñas que se adaptan a la norma de género son mejor aceptados que aquellos que la transgreden.

Así, ya en los primeros años de vida, se observa como niños y niñas tienen actitudes y comportamientos que podríamos denominar sexistas y de rechazo hacia la diversidad. En este sentido, destaca el trabajo etnográfico de Renold (2005, 2006), uno de los más clarificadores de las culturas de género y sexualidad en las aulas, y de las dinámicas de poder-resistencia que las caracterizan, realizado a lo largo de un curso académico, contextualizado en el último año de educación primaria y llevado a cabo a través de entrevistas de grupo con 59 alumnos/as (26 niños y 33 niñas) de dos colegios del sur de Inglaterra. Y en el que se ponen de relieve las consecuencias de transgredir la norma de género, yendo más allá de sus límites, especialmente en el caso de los niños; experimentando exclusión y maltrato por parte de sus compañeros/as, lo que podríamos denominar también "crueldades normativas" (Ringrose y Renold, 2009) o "heteronormativas" o también "prácticas de otredad" (Carrera, 2013).

\section{Método}

\section{Tipo de estudio}

Se realizó un estudio cualitativo con un enfoque etnográfico, en el cual los propios niños y niñas se convierten en los propios protagonistas de la investigación. Sus experiencias, creencias y opiniones son centrales en este trabajo, trascendiendo la clásica aproximación a la infancia en la cual niños y niñas son posicionados como neutrales o como espectadores/as pasivos dentro del proceso de socialización (Woodhead y Montgomery, 2003).

\section{Participantes}

Tal y como se ha destacado, el estudio se llevó en un aula de $6^{\circ}$ de Educación Infantil de un centro público de Educación Infantil y Primaria de la Comunidad Autónoma Gallega, participando un total de 24 alumnas/os (la clase en su integridad), de los cuales 12 son niños y 12 niñas, con una edad media de 5 años y tres meses y un rango de entre 5 años y 5 años y 11 meses. Pertenecientes a familias con un nivel social y económico medio-alto.

\section{Instrumentos}

Se llevó a cabo una actividad que fue seguida de una entrevista individual. Así, partiendo de los dibujos de diferentes familias y de la historia recogida en el programa virtual "Familias de Colores. Somos como
Somos. Aprendiendo y enseñando la diversidad afectiva, sexual y personal en la Educación Infantil y Primaria" (2014), coordinado por Mercedes Sánchez y editado por FELGTB Y CCOO -que a su vez se ha desarrollado a partir del manual "Cómo educar en la diversidad afectiva, sexual y personal en Educación Infantil" (2010) también de la misma autora-, se organizó una actividad desarrollada en tres fases.

En un primer momento la investigadora proyectó en la pizarra digital las imágenes de las seis familias del cuento -y relató la breve historia que describe a cada una de ellas, titulada "La casa de colores". Se presentaba: i) una familia formada por la mamá y su niño concebido por inseminación artificial; ii) una familia heterosexual formada por el papá viudo, su hija y su hijo huérfanos; iii) una familia formada por una pareja heterosexual y su futuro hijo; iv) una familia homoparental formada por dos papás y un niño adoptado; v) una familia heterosexual formada por el papá, la mamá y las dos hijas; vi) una familia homoparental, formada por dos mamás, su hijo y su perrita.

A continuación, en una segunda fase, se comentó la historia con las imágenes para ver si los niños/as la habían comprendido bien. Posteriormente, en la tercera y última fase, se presentó a cada niño/a un cuestionario formado por tres preguntas, cada una de ellas con imágenes de algunas de las diferentes familias, que tenía que responder, implicando habitualmente su respuesta una comparación entre familias: i)¿Los niños y niñas de todas las familias tienen un papá y una mamá?; ii) De las familias que aparecen a continuación, ¿cuál cuida mejor de los niños/as?, ¿por qué?; y iii.) ¿A qué familia te gustaría pertenecer?, ¿por qué?

Estas preguntas fueron realizadas por la investigadora para ayudar a los niños/as en la comprensión de las cuestiones y en el reconocimiento de las imágenes, así como para responder a ellas.

\section{Procedimiento}

Se contactó directamente con la dirección del centro planteándole el objetivo del estudio, la metodología del mismo y la importancia de su colaboración. Para ello se entregó un documento en el que se informaba por escrito de todo lo anterior y se garantizaba el anonimato y la confidencialidad de los datos, así como la finalidad estrictamente académica del estudio. Una vez que el centro aceptó colaborar, se nos asignó un aula de $6^{\circ}$ de Educación Infantil.

Concretamente, la actividad que aquí se presenta se llevó a cabo en horario lectivo en Febrero de 2014 en una sesión de dos horas de duración.

En cuanto al registro de los datos, al tratarse de niños y niñas de tan corta edad, los datos generados fueron discursos de carácter oral. Aunque la idea inicial era recoger los discursos a través de una grabación de audio, el centro no lo permitió, por lo que tuvimos que copiar literalmente las respuestas derivadas de las entrevistas individuales. Para facilitar el registro se pidió al alumnado que hablara despacio y respetando los turnos de palabra. 


\section{Resultados}

Tal y como se señaló se analizaron actitudes hacia la diversidad sexual a través del relato de una breve historia en la que se presentaban diferentes familias y de un cuestionario posterior formado por seis preguntas con sus imágenes correspondientes, aplicado individualmente a cada niña/o a través de una entrevista, y cuya respuesta implicaba habitualmente una comparación entre familias o una elección de las mismas.

Así, en la primera pregunta se preguntaba al alumnado si los niños y niñas de todas las familias del cuento tienen un papá y una mamá y se le presentaba junto a la cuestión la imagen de todas las familias de la historia. Observándose que 9 niñas y 5 niños, a pesar de haber escuchado la historia y visto los dibujos que representan a diferentes tipos de familia, responden que "sí", es decir que todos los niños y niñas tienen un padre y una madre (opción que representa el $66.7 \%$ de las respuestas).

Además, a los niños/as que contestaron "sí" se le confrontó su respuesta mostrándoles algunas familias de la historia ("Pero, por ejemplo, en la familia del $2^{\circ}$ izquierda y en la del $1^{\circ}$ derecha hay dos papás y dos mamás ¿No lo ves?”) Ante esta confrontación la mayoría de los niños y las niñas se limitaron a afirmar que "sí" lo veían, aunque con poca credulidad, pero no cambiaron su respuesta. Por otra parte, otros niños/as contestaron sorprendidos que " $\mathrm{OOh}$ sí, mira aquí hay dos papás!" (Víctor, línea 1404), e incluso uno de los niños afirmó que “¡Hay que cambiarlos!” (Antonio, línea 1317), refiriéndose a que los dibujos que representaban a familias homoparentales estaban mal y había que cambiarlos.

Por otra parte, 3 niñas y 4 niños contestaron que no a la pregunta, señalando que no todos los niños y las niñas tienen un papá y una mamá $(33.3 \%$ del total de las respuestas). Identificando algunas familias en las que hay dos papás “...en el segundo izquierda tienen dos papás" (Roberto, línea 1291); así como algunas familias en las que hay dos mamás, como por ejemplo "Algunos no. Mira, en el primero derecha no hay papás” (Iván, línea 1433).

A continuación, se presentaron otras tres familias (la familia monoparental formada por el papá viudo, su hija y su hijo huérfanos; la familia homoparental formada por dos papás y un niño adoptado; y la familia heterosexual formada por el papá, la mamá y las dos hijas) y se les preguntó cuál de ellas cuida mejor de los niños/as y por qué. Las respuestas dadas por el alumnado fueron muy variadas siendo la familia heterosexual la más elegida con un $62 \%$ del alumnado ( 8 niñas y 5 niños). En sus argumentaciones, cinco niñas señalaron que la escogían, entre otros motivos, "porque son felices" (Adriana, línea 1076) o "porque la madre es guapa" (Nerea, línea 1019). Con respecto a los niños, estos destacaron que eligieron esta opción "porque no le están haciendo nada al niño" (Antonio, línea 1370), "porque son cuatro" (Gonzalo, línea 1388) o simplemente "porque si" (Alejandro, línea 1359).
La familia monoparental ocupa el $23.8 \%$ de las elecciones (con 3 niñas y 2 niños). En cuanto a las niñas, una de ellas lo justificó "porque son felices" (Olga, línea 1218) y dos de ellas no justificaron su respuesta. En cuanto a los niños, dos niños eligieron a esta familia (22.2\%) "porque se portan bien" (Rubén, línea 1275).

La tercera familia, homoparental, formada por "gays", ocupa el 14.2\% del total de elecciones, siendo escogida por una niña "porque tiene un hijo" (Marta, línea 1047) y por dos niños que argumenta que la escogen: "porque hay dos papas" (Sergio, línea 1247) y "porque son felices" (Iván, línea 1447).

Por último, en la siguiente cuestión se le preguntaba a qué familia, de las que se presentaban a continuación, le gustaría pertenecer y por qué (incluyendo las imágenes de la familia formada por la mamá y su niño concebido por inseminación artificial; la familia homoparental formada por dos papás y su niño adoptado; y la familia formada por una pareja heterosexual y su futuro hijo). Sus respuestas ponen de manifiesto que a la mayoría de los niños y de las niñas $(62 \%)$ le gustaría pertenecer a la familia monoparental formada por la madre y el bebé. En lo que respecta a las niñas nueve de ellas eligieron esta familia, de las cuales siete argumentaron su elección "porque tiene un bebé" (Rebeca, línea 910), una "porque cuida mucho a su bebé" (Lidia, línea 997) y otra no sabe muy bien la causa de su elección y responde "porque si". En lo que respecta a los niños, cuatro de ellos se decantaron por esta familia, dos de ellos "porque si" (Roberto, línea 1309), otro "porque tiene un bebé" (Víctor, línea 1425) y por último "porque son dos" (Rubén, línea 1283).

La familia heterosexual, representada por una pareja y un futuro bebé constituye el $28.6 \%$ de la elección de todos los sujetos. Las dos niñas que eligieron esta familia explican su elección en argumentos tales como "porque van a tener un bebé" (Olga, línea 1226) o "porque si" (Tamara, línea 968). En cuanto a los cuatro niños que escogieron a esta familias, uno utiliza el argumento de "porque van a tener un bebé" (Gonzalo, línea 1396), otro "para que no estén solos" (Iván, línea 1451) y dos responden con un simple "porque si" (Jose, línea 1479).

Respecto a la familia homoparental formada por una pareja de "gays", tan solo un niño expresó esta elección, aunque sin razonar su respuesta. Otra respuesta fue la de María que dijo que no le gustaría pertenecer a ninguna familia "porque son todos muy feos" (María, línea 1168).

\section{Discusión}

Los resultados ponen de relieve que, en general, los niños/as niegan la existencia de la homoparentalidad, así aún después de relatar la historia en la que aparecen familias homoparentales, los niños/as niegan esta evidencia (vemos que más de dos tercios dicen que todos los niños y niñas tienen un papá y una mamá), pues están total y absolutamente socializados en la heteronorma (Butler, 1990, 1993; Renold, 2005). 
Asimismo, señalan que la familia que mejor cuida de los niños/as es la heterosexual. De nuevo se observa que las familias homoparentales de gays no son las más valoradas, escogiéndose en último lugar como las que mejor cuidan a los niños/as. Tal vez en este caso influyan también los estereotipos de género -en estrecha relación con la heteronorma- según los cuales los hombres están menos preparados para el cuidado de la prole (Lameiras et al., 2013). Asimismo, llama la atención una de las motivaciones dadas por uno de los niños del trabajo que escoge a la familia heterosexual porque "no le están haciendo nada a los niños", desprendiéndose de aquí la idea de la familia homoparental como negligente o patológica para la crianza de los niños/as.

En la misma línea, cuando se le pregunta a qué familia les gustaría pertenecer, la familia homoparental formada por dos padres gays es la que obtiene menos elecciones. Y si bien es cierto que la familia monoparental formada por la mamá y el bebé es la más escogida, seguida de la heterosexual, no debemos asumir sin más que los modelos "diferentes" de familia están empezando a ser más aceptados por los niños y las niñas, sino que es el "bebé" el elemento que hace a los/as participantes decantarse por esta familia, tal y como ponen de manifiesto sus comentarios, y al igual que se comprueba en el trabajo de Pichardo (2014)

Estas respuestas y elecciones, en la línea del rechazo social hacia las familias homosexuales, ponen de manifiesto la necesidad de una práctica educativa orientada a la promoción de actitudes positivas hacia la diversidad sexual desde la infancia.

\section{Referencias}

Butler, J. (1990). Gender trouble: feminism and the subversion of identity. London and New York: Routledge.

Butler, J. (1993). Bodies that Matter: On the Discursive Limits of "Sex". London and New York: Routledge.

Carrera, M.V. (2013). Educando Queer: el educador/a social como agente de subversión de género en la escuela. Revista Iberoamericana de Educación, 61, 2-12.

Carrera, M.V., Rodríguez, Y., Lameiras, M., Vallejo, P. y Alonso, P. (2013). Actitudes hacia la diversidad sexual en estudiantes de secundaria españoles. Revista Iberoamericana de Salud y Ciudadanía, 2, 110-128.

Lameiras, M., Carrera, M.V. y Rodríguez, Y. (2013). Sexualidad y salud. El estudio de la sexualidad humana desde una perspectiva de género. Vigo: Servizo de Publicacións da Universidade de Vigo.

Pichardo, J.I (Coord.) (2014). Diversidad sexual y convivencia: una oportunidad educativa. Madrid: Universidad Complutense de Madrid.

Renold, E. (2005). Girls, boys and junior sexualities: exploring children's gender and sexual relations in the primary school. London: Routledge.

Renold, E. (2006). "They won't let us play...unless you're going out with one of them": girls, boys and
Butler's "heterosexual matrix" in the primary years. British Journal of Sociology of Education, 27, 489509.

Ringrose, J. y Renold, R. (2009). Normative cruelties and gender deviants: the performative effects of bully discourses for girls and boys in school. British Educational Research Journal, 4, 1-24.

Rodríguez, Y., Lameiras, M., Carrera, M.V. y Magalhaes, M.J. (2012). Los estereotipos de género y la imagen de la mujer en los mass media. En I. Iglesias y M. Lameiras (Coords.), Comunicación y justicia en Violencia de Género (p 37-67). Valencia: Tirant lo blanch

Sánchez-Sainz, M. (2010). Cómo educar en la diversidad afectiva, sexual y personal en Educación Infantil. Madrid: Catarata

Sánchez-Sainz, M. (Coord.) (2014). Familias de Colores. Somos como Somos. Aprendiendo y enseñando la diversidad afectiva, sexual y personal en la Educación Infantil y Primaria. Barcelona: FELGTB.

Theimer, E., Killen, M. y Stangor, C. (2001). Young Children's Evaluations of Exclusion in GenderStereotypic Peer Contexts. Developmental Psychology, 37, 18-27

Woodhead, M y Montgomery, H. (2003) Understanding Childhood: An interdisciplinary approach. Chichester: John Wiley. 